\title{
A EDUCAÇÃO AMBIENTAL EM PERIÓDICOS BRASILEIROS DE ENSINO DE FÍSICA
}

Patrik Sudário de Souza Pereira ${ }^{1}$

Ivan Fortunato ${ }^{1}$

Caroline Lourenço ${ }^{1}$

Resumo: Nesta pesquisa, foi estudada a relevância dada à Educação Ambiental em revistas de ensino de física. Realizou-se um mapeamento, do período do ano de 2000 até 2014, analisando dois periódicos - a Revista Brasileira de Ensino de Física e o Caderno Brasileiro de Ensino de Física buscando artigos pertinentes ao tema. Em seguida, foi feita análise qualitativa explorando ano de publicação, titulação de seus autores, foco temático, metodologias empregadas e referencial teórico. Apenas 0,52\% das publicações do período tratavam da temática em questão, evidenciando acentuada lacuna existente nestas revistas, no que se refere à Educação Ambiental.

Palavras-chave: Educação Ambiental; Ensino de Física; Mapeamento.

1 Núcleo de Estudos Transdisciplinares em Ensino, Ciência, Cultura e Ambiente (NuTECCA) - IFSP, Itapetininga. E-mail: ivanfrt@yahoo.com.br

revista brasileira educação ambiental 


\section{Introdução}

Este artigo apresenta resultado de pesquisa de Iniciação Científica desenvolvida no Instituto Federal de Educação, Ciência e Tecnologia São Paulo, o IFSP, câmpus de Itapetininga. Para cumprir seus objetivos sociais, o IFSP baseia suas atividades no tripé: ensino, pesquisa, e extensão. A educação superior deve profissionalizar, iniciar à prática científica e formar a consciência político-social do estudante. Ensinar e prestar serviços à comunidade são tarefas da universidade, as quais devem ser realizadas, tendo como fonte alimentadora na produção de conhecimento (SEVERINO, 2007, p. 22-23).

Nesse sentido, com o objetivo de fomentar a contribuição social do IFSP, câmpus Itapetininga, criou-se, no ano de 2014, o Núcleo de Estudos Transdisciplinares em Ensino, Ciência, Cultura e Ambiente, o NuTECCA. De imediato, os pesquisadores do NuTECCA identificaram a necessidade de se articular pesquisas relacionadas à temática ambiental. Tal necessidade emerge da Lei Nacional 9.795, de 27 de abril de 1999, que estipula que a educação ambiental seja uma temática indispensável e permanente da educação nacional, devendo estar presente, de forma articulada e transdisciplinar, em todos os níveis e modalidades do processo educativo, desde o ensino infantil até o ensino superior, seja com caráter de educação formal ou informal, de modo a favorecer a construção de valores, conhecimentos e habilidades voltadas para a conservação do meio ambiente.

Ainda, tendo em vista que este câmpus ${ }^{2}$ oferece curso de Licenciatura em Física, pretende-se que este grupo de pesquisas desenvolva trabalhos sobre meio ambiente ligados, entre outras áreas, à esta ciência. No entanto, a análise do currículo discriminado no projeto pedagógico do próprio curso levou à constatação de que a Educação Ambiental era pouco, senão em absoluto, contemplada pela primeira versão deste documento, apresentada em 2010. Essa ausência também foi destaca por Moita Netos e Santos (2011), ao notarem que, no curso de Licenciatura em Física da Universidade Federal do Piauí, havia somente uma disciplina que tratava especificamente de temáticas ambientais, porém era optativa e nunca foi ministrada em virtude do desinteresse dos alunos em reivindicá-la.

Assim, ao considerar a notória necessidade de se pensar cada vez mais "ambientalmente", a existência de uma lei nacional que institui a presença da Educação Ambiental, de forma articulada e transversa na educação formal, e a ausência de referências da educação ambiental nos projetos pedagógicos de cursos de licenciatura em física, identificou-se uma contundente lacuna no que tange aos objetivos sociais de uma formação qualificada. Deste contexto, emergiu a necessidade de qualificar esta lacuna como algo particular ou universal. Nesse sentido, realizamos um mapeamento completo da temática

2 Esta é a grafia adota pela reitora do Instituto.

Revbea, São Paulo, V.11, № 2: 127-138, 2016. 
ambiental em alguns dos mais importantes periódicos nacionais especializados no ensino de física.

O objetivo deste mapeamento foi identificar o atual estado da arte sobre a relação entre ensino de física e Educação Ambiental. A expectativa é que este estado da arte auxilie as instituições na reelaboração de seus currículos para adequação à lei nacional, bem como fornecer subsídios à ação do professor de física no que diz respeito à própria Educação Ambiental. Para alcançar nossos objetivos, primeiro descrevemos nossa metodologia de pesquisa; em seguida, apresentamos e discutimos os dados obtidos que, por sua vez, ratificam a lacuna identificada: há poucos trabalhos sobre Educação Ambiental nos periódicos especializados.

\section{Materiais e métodos}

A ideia de realizar o levantamento veio da leitura do artigo de Carvalho e Farias (2011), intitulado "Um balanço da produção científica em educação ambiental de 2001 a 2009 (ANPEd, ANPPAS e EPEA)". O objetivo de tal levantamento foi fundamentar uma discussão à cerca da legitimação da Educação Ambiental como área de produção científica. Neste texto, foram selecionadas e analisadas produções científicas relacionadas à Educação Ambiental apresentados em três bases diferentes, que foram a

Associação Nacional de Pós-Graduação e Pesquisa em Educação (ANPEd), a Associação Nacional de Pós-graduação e Pesquisa em Ambiente e Sociedade (ANPPAS) e o Encontro de Pesquisa em Educação Ambiental (EPEA). Dos artigos pertinentes para os objetivos propostos pelo levantamento desses autores, foram estudados e descritos os seguintes atributos: características do autor (gênero, titulação e universidade a que é vinculado e região onde esta se localiza) e ênfase temática abordada - este, realizado com base nos resumos e palavras-chaves e com auxílio de categorias temáticas construídas pelos próprios autores.

Assim como Carvalho e Farias (2011) realizaram sua busca em bases qualificadas, para este mapeamento, a escolha dos periódicos atendeu a três atributos: a especificidade de seu foco e escopo, ou seja, o ensino de física; a acessibilidade, isto é, apresentam seus artigos de forma online e gratuita; e sua classificação no webqualis ${ }^{3}$. Nesse sentido, há dois periódicos que atendem aos três atributos: a Revista Brasileira de Ensino de Física e o Caderno Brasileiro de Ensino de Física.

A Revista Brasileira de Ensino de Física (RBEF), classificada como A1 no webqualis ${ }^{4}$, é vinculada à Sociedade Brasileira de Física e possui rico

\footnotetext{
3 Plataforma gerenciada pela CAPES (2014) que consiste num sistema de classificação de periódicos nacionais e internacionais. Os periódicos são classificados em estratos $A 1, A 2, B 1$, B2, B3, B4, B5 e C, sendo A1 atribuído como nível mais elevado e C como nível mais baixo.

${ }^{4}$ De acordo com a "classificação de periódicos 2012", acesso em 14 out. 2015.
} 
acervo de artigos relacionados ao ensino de Física, visando melhorias nessa área desde o ensino fundamental até o superior. Com quatro edições anuais, a RBEF contempla todos os temas da Física abordados por diferentes enfoques e estudados através de diversas metodologias.

O Caderno Brasileiro de Ensino de Física (CBEF), com índice B1 no webqualis $^{5}$, é vinculado à Universidade Federal de Santa Catarina (UFSC) e, tal qual a RBEF, pretende contribuir na área de Ensino de Física com publicações de artigos, estes realizados quadrienalmente.

Para realizar o mapeamento, foram acessadas as plataformas online de artigos das revistas. Foram revisados artigos publicados desde o ano 2000 até o ano 2014, e selecionados aqueles que abrangiam o tema da Educação Ambiental. Para isso, foram lidos os resumos de todos os artigos publicados pelas revistas e utilizada ferramenta de busca de palavras a fim de se identificar quais deles apresentavam a temática desejada.

Os procedimentos consistiram nas seguintes etapas:

1. Mapeamento dos artigos que abrangem a temática ambiental publicados em ambas as revistas de 2000 até 2014 (tabelas 1 e 2). Iniciamos a busca no ano 2000, pois é o ano que segue a promulgação da Lei Nacional 9.795;

2. Qualificação das características dos autores quanto à escolarização e instituição (tabelas 3 e 4);

3. Análise dos artigos quanto às referências utilizadas, natureza de pesquisa utilizada e foco temático (tabelas 5 e 6);

4. Apreciação qualitativa dos artigos encontrados.

\section{Resultados e discussão}

A primeira etapa da pesquisa consistiu no mapeamento quantitativo dos artigos. A Tabela 1 (próxima página) indica o total de artigos publicados desde 2000, e a porcentagem de artigos pertinentes ao tema ambiental, sendo que não foi possível observar presença significativa nos periódicos.

A Tabela 2 (próxima página) mostra a distribuição dos artigos em relação aos anos em que foram publicados nas revistas.

Após realizar o mapeamento dos artigos, iniciamos a segunda etapa da pesquisa. Assim, foi efetuado o reconhecimento das características dos autores quanto à formação no ano em que produziram os artigos para podermos traçar um perfil dos pesquisadores de Física que se interessam pela área de Educação Ambiental. A Tabela 3 (próxima página) informa tais atributos.

${ }^{5}$ De acordo com a "classificação de periódicos 2012", acesso em 14 out. 2015.

Revbea, São Paulo, V.11, № 2: 127-138, 2016. 
Tabela 1: Total de Artigos e porcentagem de artigos que abordam tema.

\begin{tabular}{cccc}
\hline Edições & Artigos Publicados & Artigos Pertinentes & Porcentagem (\%) \\
\hline 2000 & 97 & 0 & 0 \\
2001 & 82 & $\mathbf{2}$ & 2,44 \\
2002 & 90 & $\mathbf{1}$ & 1,11 \\
2003 & 70 & 0 & 0 \\
2004 & 124 & $\mathbf{1}$ & 0,81 \\
2005 & 96 & 0 & 0 \\
2006 & 74 & 0 & 0 \\
2007 & 100 & $\mathbf{1}$ & 1 \\
2008 & 93 & 0 & 0 \\
2009 & 98 & 0 & 0 \\
2010 & 105 & $\mathbf{1}$ & 0,95 \\
2011 & 119 & $\mathbf{1}$ & 0,84 \\
2012 & 133 & 0 & 0,75 \\
2013 & 139 & 0 & 0 \\
\hline 2014 & 105 & $\mathbf{8}$ & 0 \\
\hline TOTAL & $\mathbf{1 5 2 5}$ & $\mathbf{1}$ & $\mathbf{0} 2$ \\
\hline
\end{tabular}

Fonte: autoria própria.

Tabela 2: Classificação dos artigos em relação ao ano de publicação.

\begin{tabular}{ccccccccc}
\hline & 2001 & 2002 & 2004 & 2007 & 2010 & 2011 & 2012 & TOTAL \\
\hline CBEF & 1 & 0 & 1 & 0 & 1 & 0 & 0 & \multirow{8}{*}{} \\
RBEF & 1 & 1 & 0 & 1 & 0 & 1 & 1 & \\
\hline
\end{tabular}

Fonte: autoria própria.

Tabela 3: Nível acadêmico dos autores dos artigos.

\begin{tabular}{cccc}
\hline ANO & Graduação & Mestrado & Doutorado \\
\hline 2001 & & 1 & 2 \\
2002 & & 1 & 1 \\
2004 & 1 & 1 & 1 \\
2007 & & & 1 \\
2010 & & 1 & 1 \\
2011 & & & 1 \\
\hline 2012 & & $\mathbf{4}$ & $\mathbf{9}$ \\
\hline TOTAL & $\mathbf{1}$ &
\end{tabular}

Fonte: autoria própria.

Em geral, os trabalhos foram produzidos por pesquisadores de pósgraduação, não havendo participação significativa de alunos de graduação. Cerca de $90 \%$ dos autores são formados em Física

Foram verificadas também quais eram as universidades às quais são vinculados cada autor, a fim de sabermos onde se concentram predominantemente as pesquisas que relacionam Ensino de Física com a Educação Ambiental. A dispersão dos artigos por várias instituições nacionais, e até estrangeira, permite inferir que não há, até o momento nenhum grupo de pesquisas ou centro de excelência que divulguem suas pesquisas sobre EA e 
ensino de física nos periódicos específicos e de maior visibilidade do país. A tabela 4 a seguir expõe estes resultados.

Tabela 4: Disposição dos autores quanto às universidades a que pertence.

\begin{tabular}{lccccccc}
\hline & $\mathbf{2 0 0 1}$ & $\mathbf{2 0 0 2}$ & $\mathbf{2 0 0 4}$ & $\mathbf{2 0 0 7}$ & $\mathbf{2 0 1 0}$ & $\mathbf{2 0 1 1}$ & $\mathbf{2 0 1 2}$ \\
\hline UNESP & 2 & 1 & & & & & \\
UNIV. DE VALENCIA & 1 & & & & & & \\
USP & & & 1 & & & & \\
UFSCAR & & 1 & & 2 & & & \\
UFGRS & & & & 2 & & \\
UNIFEI & & & & & 1 & 2 & \\
UESC & & & & & & & \\
UFPI & & & & & & & \\
UNICAMP & $\mathbf{3}$ & $\mathbf{2}$ & $\mathbf{1}$ & $\mathbf{2}$ & $\mathbf{3}$ & $\mathbf{2}$ & $\mathbf{1}$ \\
\hline TOTAL & & & & & & &
\end{tabular}

Fonte: autoria própria.

Concluída a fase de identificação da formação e instituição de origem dos autores, iniciou-se a terceira etapa da pesquisa, na qual foram cotejadas as referências bibliográficas pelos autores dos artigos, tencionando localizar bases comuns para a educação ambiental no ensino de física. No entanto, a análise mostrou que não existe um referencial consolidado, pois nenhuma referência bibliográfica em comum foi encontrada, ratificando a diversidade de concepções e possibilidades de pesquisa em Educação Ambiental.

Finalizado este procedimento, realizou-se uma análise quantiqualitativa dos artigos levando em conta suas metodologias e foco temático, tendo por base o mesmo critério utilizado por Fernandes e Kawasaki (2012), que qualificaram os artigos de sua pesquisa nas seguintes categorias: Ensaio; Estudo de Caso; Pesquisa Etnográfica; Pesquisa-Ação Participante; Pesquisa Fenomenológica; Pesquisa Documental.

Essa análise dos artigos pertinentes do CBEF e da RBEF encontra-se na Tabela 5 , a seguir, que trata sobre a natureza da pesquisa utilizada nos artigos encontrados. Seguiu-se a definição dada pelos seus próprios autores, de acordo com o tipo de abordagem metodológica explicitada. De acordo com o levantamento expresso na tabela, é possível constatar, tal qual Fernandes e Kawasaki (2012), que há predominância de pesquisas em caráter documental, e baixa porcentagem de pesquisas empíricas ou de intervenção.

Tabela 5: Distribuição dos trabalhos em relação à natureza da pesquisa.

\begin{tabular}{cc}
\hline Natureza da pesquisa & Artigos \\
\hline Ensaio & 2 \\
Pesquisa Documental & 4 \\
\hline Pesquisa-ação & 2 \\
TOTAL & $\mathbf{8}$ \\
\hline
\end{tabular}

Fonte: autoria própria. 
Por fim, a análise recaiu sobre o foco temático dos artigos pertinentes, principalmente a partir de seus resumos e palavras-chave. Para esta análise, adotou-se a seguinte categorização de Carvalho e Farias (2011) para pesquisas de Educação Ambiental, indicando nove (09) possibilidades:

(A.) EA no ensino formal;

(B.) EA na formação de professores;

(C.) EA na gestão ambiental;

(D.) EA popular e/ou comunitária;

(E.) EA e subjetividades/identidades;

(F.) EA nas mídias, artes e outras expressões culturais [basicamente, a EA na educação não-formal];

(G.) Fundamentos da EA [pesquisas epistemológicas ou de estado da arte];

(H.) Os sentidos da EA [pesquisas de representações sociais, culturais e de percepção];

(I.) EA no debate ambiental [a presença da EA em outros campos ambientais, como desenvolvimento sustentável, conflitos ambientais, direito ambiental, aquecimento global, turismo ecológico etc.].

Tabela 6: Foco temático dos artigos pertinentes.

\begin{tabular}{cc}
\hline Categoria & Artigos \\
\hline EA no ensino formal & 2 \\
Ea na formação de professores & 1 \\
Fundamentos da EA & 1 \\
EA nas mídias, artes e outras expressões culturais & 1 \\
EA no debate ambiental & 3 \\
\hline TOTAL & $\mathbf{8}$ \\
\hline
\end{tabular}

Fonte: autoria própria.

\section{O "achado" da pesquisa: a relação entre ensino de física e EA}

Diante a "escassez" de artigos que relacionam o ensino de física com a Educação Ambiental, disponíveis nos importantes periódicos mapeados nesta pesquisa, torna-se fundamental examinar qualitativamente essa produção. Justamente por ser tão dispersa ao longo de mais de uma década, aliada ao fato de serem artigos isolados, sem qualquer continuidade por parte dos pesquisadores, ou relação entre estes, a análise qualitativa pode elucidar futuras pesquisas sobre a temática - objetivando suprir essa importante lacuna no ensino de física. Conforme já exposto, foram localizados oito (08) artigos, sendo três (03) do CBEF e cinco (05) da RBEF. Para facilitar a leitura, a apresentação da análise dos artigos foi feita por periódico, e na sequencia cronológica, do mais antigo ao mais recente. 


\section{Caderno Brasileiro de Ensino de Física}

1. O artigo mais antigo, publicado em 2001, é "El ozono atmosférico, ¿benefactor o malhechor?”. Foi escrito pelo Prof. Dr. Joan Josep SolazPortolés, licenciado em Ciências Químicas pela Universidade de Valência. Este artigo pode ser considerado um Ensaio teórico, cujo foco temático é a EA no debate ambiental. Através de revisão bibliográfica sobre o tema, o autor comenta sobre a presença gás ozônio na atmosfera, desde a troposfera até a estratosfera, e sua importância na retenção dos raios ultravioletas provenientes do Sol. Afirma-se que, em cem anos, a concentração de ozônio mais do que duplicou, até mesmo em áreas rurais, principalmente no verão. Atribui o aumento da concentração de ozônio às atividades antrópicas, como a queima de combustíveis fósseis, mencionando possíveis consequências da alteração na quantidade do ozônio atmosférico. Sua redução, por exemplo, aumentaria a intensidade de radiação ultravioleta proveniente do sol, potencializando a chance de a população desenvolver queimaduras e até câncer de pele; além de alterar as condições climáticas do planeta. Por outro lado, o aumento da concentração pode causar outros problemas como chuva ácida, emissão de radicais livres que podem atacar plantas ou animais. Por fim, propõe práticas de EA tais como: evitar uso de aerossóis que tenham CFC, utilização de transporte público, etc.

2. O artigo "A análise do efeito estufa em textos para-didáticos e periódicos jornalísticos", publicado em 2004, foi produzido pelos físicos da USP, Prof. Dr. Américo Kerr e Maria Emília Corrêa Rehder Xavier, graduada na época da publicação. Este trabalho pode ser classificado como "pesquisa documental", cujo foco temático é a EA nas mídias, artes e outras expressões culturais. Os autores analisaram textos não ligados ao âmbito acadêmico e buscaram encontrar, bem como corrigir, prováveis falhas que poderiam levar os leitores a uma compreensão errônea sobre o fenômeno do efeito estufa. Tais erros consistiam, principalmente, em informações que negligenciavam o efeito estufa como essencial para a vida na Terra, apresentando exclusivamente seus malefícios. Outro equívoco notado pelos autores foram afirmações sobre o efeito estufa como produto exclusivo da ação antrópica, ignorando as causas naturais e espontâneas deste. Ademais, seus autores trataram da incoerência entre as críticas feitas a um efeito climático, cuja intervenção humana não seria comprovadamente tão acentuada, e a ausência de análises sobre fenômenos culturais, como o trânsito caótico em várias cidades. Para encerrar, os autores avaliaram os prejuízos econômicos causados por uma possível mudança radical nas fontes energéticas - como rejeição total ao uso de combustíveis fósseis - concluindo que estes seriam piores que os danos ambientais supostamente causados pelo seu uso. 
3. Em 2010, foi publicado o artigo "Mudanças climáticas: reflexões para subsidiar esta discussão em aulas de Física". Seus autores são os físicos Agenor Pina da Silva, doutor em física pela USP, Luciano Fernandes Silva, doutor em educação pela UNESP, e Zolacir Trindade de Oliveira Júnior, doutor em física pela UNICAMP. Pode ser considerado uma Pesquisa Documental, cujo foco temático é a EA no ensino formal. Os autores realizaram uma revisão bibliográfica com 0 objetivo de demonstrar que diversos conceitos relacionados ao meio ambiente não poderiam ser considerados como consenso para a comunidade científica. Outro objetivo foi o de expor pontos de vista adversos relacionados à responsabilidade da ação humana sobre o aumento da taxa de $\mathrm{CO}_{2}$ na atmosfera. Por isso, um dos conceitos trazidos como exemplo de dissenso foi o "efeito estufa": pois de um lado haveria carência da divulgação de informações a respeito de suas causas naturais e, do outro, excesso de conteúdo sobre uma possível imprudência humana, destruindo o "cobertor" de gases que retém a saída do calor.

\section{Revista Brasileira de Ensino de Física}

1. Em 2001 foi publicado o artigo "Análise do uso de um texto paradidático sobre energia e meio ambiente", produzido pelas físicas Alice Assis, mestre em educação para ciência, e por Odete Pacubi Baierl Teixeira, doutora em educação pela USP. Este pode ser considerado uma Pesquisa Ação, cujo foco foi Fundamentos de EA. O projeto consistiu em levar para alunos da segunda série do Ensino Médio conteúdos contextualizados sobre Educação Ambiental, a partir da leitura de um livro paradidático sobre energia e meio-ambiente. As autoras analisaram a apropriação de noções básicas de energia por parte dos alunos, a conscientização ambiental deles e a influência da leitura na atividade em sala de aula. Para efetuar esta análise, foram aplicados questionários, uma entrevista e uma proposta de redação. É interessante destacar que a leitura do livro foi feita sem mediação do professor a fim de que este não influenciasse demasiadamente nas respostas dos alunos. $O$ resultado foi considerado satisfatório pelas autoras, haja vista que mesmo alguns alunos não demonstrando plena compreensão sobre a parte conceitual de energia, a leitura propiciou-lhes reflexão a cerca da temática ambiental, e ampliação do nível de consciência em relação aos problemas ambientais.

2. O artigo "A temática ambiental e o ensino de física na escola Média: algumas possibilidades de desenvolver o tema produção de energia elétrica em larga escala em uma situação de ensino", publicado em 2002, foi escrito por Luciano Fernandes Silva e pelo Prof. Dr. Luiz Marcelo de Carvalho, biólogo e doutor em educação. Este artigo pode ser classificado como Pesquisa Documental, cujo foco foi EA no ensino 
formal. O objetivo central dessa pesquisa foi sintetizar as discussões realizadas em meio técnico e acadêmico sobre o assunto ambiental e a produção de energia elétrica em larga escala. Os autores fizeram uma revisão bibliográfica que possibilitou o levantamento de informações sobre a realidade e conteúdos que poderiam ser abordados em sala de aula. Dentre as informações selecionadas e que podem ser trabalhadas, destacam-se: as consequências ambientais para implantação de hidrelétrica; termelétrica utilizar combustível fóssil e afetar efeito estufa, chuva ácida, energia solar, energia eólica, dentre outras. Por fim, destaca-se a importância da abordagem de diferentes formas de produção de energia e a temática ambiental. Para tal abordagem, assuntos relativos às diferenças de custo, disponibilidade para a sociedade e seus fatores de risco, vantagens e desvantagens, são aspectos fundamentais que podem auxiliar o professor de física em sua abordagem do conteúdo em sala de aula dando condições aos seus alunos de analisar e interpretar esses fenômenos da produção de energia de forma consciente e crítica.

3. Em 2007 foi publicado o artigo "Ensinando Física com consciência ecológica e com materiais descartáveis" pelos físicos Felipe Damasio, e mestre em ensino de Física e pela Profa. Dra. Maria Helena Steffani, ambos da UFRGS. Pode ser classificado como Pesquisa-ação, cujo foco foi EA no debate ambiental. Seu objetivo foi conscientizar a população à cerca dos problemas ambientais relacionados ao aquecimento global, inserindo as pessoas em ações engajadas quanto à preservação do meio ambiente. Uma dessas ações foi a construção de um aquecedor solar, numa escola pública, com materiais descartáveis que possibilitaria banhos quentes sem gasto de energia elétrica. A metodologia aplicada foi patenteada pelos autores, na qual embalagens de longa vida são colocadas no teto de uma casa com a finalidade de absorver energia solar, posteriormente convertida em energia térmica para aquecer a água das caixas. Ao final deste trabalho, os alunos da segunda série do ensino médio explicaram para seus colegas o funcionamento do equipamento. Diferentemente dos textos paradidáticos criticados pelos artigos anteriores, este artigo deixa claro que o efeito estufa, até certo ponto, é fundamental para a vida, porém afirma que este efeito tem se intensificando devido ao aumento da emissão de gás carbônico na atmosfera.

4. O artigo "A perspectiva ambiental no curso de licenciatura de física da UFPI: reflexões sobre o atual projeto politico pedagógico" foi publicado em 2011 pelo Prof. Dr. José Machado Moita Neto, e pela Profa. Dra. Karine dos Santos, ambas pela UFPI. Este artigo pode ser classificado como Pesquisa Documental, cujo foco temático foi Educação Ambiental na formação de professores. Os autores analisam o Projeto Político Pedagógico da Universidade Federal do Piauí com o objetivo de discutir, 
defender e propor caminhos a serem seguidos no que tange ao tema meio-ambiente, em relação ao curso de Licenciatura em Física da instituição. Havia, na ocasião, na UFPI uma diretriz que previa uma disciplina optativa sobre tópicos físico-ambientais em sua grade curricular, em uma matéria optativa com duração de 60h. Entretanto, mesmo a disciplina estando no currículo acadêmico do curso de física, ela nunca havia sido ministrada, pois não havia procura $e$, consequentemente, oferta da disciplina. Para os autores, essa referida disciplina deveria ser obrigatória.

5. O artigo mais recente, publicado em 2012, tem como título "Modelo adiabático da atmosfera terrestre compatível com o aquecimento global e o efeito estufa". Foi produzido por pelo Prof. Dr. Mario Tosi Furtado, graduado e pós-graduado em Física pela PUC-RJ. Este artigo pode ser considerado um ensaio teórico, cujo foco temático foi EA no debate ambiental. $\mathrm{O}$ autor descreve o aquecimento global proveniente do efeito estufa, cujo maior responsável é o dióxido de carbono. Retoma Arrhenius que, em 1896, foi um dos primeiros a propor uma que teoria que descreve como a queima de combustíveis fósseis libera gás carbônico, que absorve a radiação infravermelha emitida pela superfície terrestre, aquecendo o planeta. Em seguida, menciona pesquisas que negam não apenas que a atitude antrópica tenha influência no aquecimento global, como negam a própria ideia de aquecimento. O objetivo deste artigo foi contestar essas pesquisas contraditórias, utilizando para isso um modelo adiabático, no qual, para efeito de simplificação, considera a atmosfera terrestre como um gás ideal e homogêneo.

\section{Considerações provisórias}

Nesse momento, salutar retomar o índice identificado: apenas 0,52\% dos artigos publicados, nos respeitados periódicos selecionados para este mapeamento, trataram da EA, revelando contundente lacuna nos estudos da área de Ensino de Física. Tal distanciamento entre a necessidade latente da conjuntura atual e a importância basilar da formação de professores é um alerta para que novas e mais densas pesquisas sejam realizadas, tanto para esclarecer motivos desse vazio, quanto para sanar essa deficiência em uma área que tanto pode contribuir para ações direcionadas para mitigação de problemas ambientais.

Pensar nas relações entre Educação Ambiental e a formação de professores para o Ensino de Física é uma das metas do NuTECCA para este ano de 2016 que se inicia. Mas, fica o convite para que colegas pesquisadores se debrucem sobre a temática, e encorajem os licenciados a perseguirem essa via, tão necessária para os desejos de um Futuro Comum. 


\section{Agradecimentos}

Ao Instituto Federal de Educação, Ciência e Tecnologia de São Paulo, câmpus Itapetininga, pelo apoio financeiro à pesquisa, por meio de bolsas de Iniciação Científica.

\section{Referências}

BENJAMIN, A.A.; TEIXEIRA, O.P.B. Análise do uso de um texto paradidático sobre energia e meio ambiente. Revista Brasileira de Ensino de Física, São Paulo, v. 33, n. 1, p. 74-82, jan./2001.

CARVALHO, I.C.M.; FARIAS, C.R O. Um balanço da produção científica em educação ambiental de 2001 a 2009 (ANPEd, ANPPAS e EPEA). Revista Brasileira de Educação, Rio de Janeiro, v. 16 n. 4, p. 119-134, jan.-abr./ 2011.

FERNANDES, J.A.B.; KAWASAKI, C.S. A pesquisa em educação ambiental e questões metodológicas: relato do grupo de discussão de pesquisa no VI EPEA. Pesquisa em Educação Ambiental (Online), Rio Claro, v. 7, p. 91-103, 2012.

FURTADO, M.T. Modelo adiabático da atmosfera terrestre compatível com o aquecimento global e o efeito estufa. Revista Brasileira de Ensino de Física, São Paulo, v. 34, n. 3, p. 3310.1-3310-13, jan./2012.

MOITA, J.M.N.; SANTOS, K. A perspectiva ambiental no curso de Licenciatura em Física da UFPI: Reflexões sobre o atual Projeto Político Pedagógico. Revista Brasileira de Ensino de Física, São Paulo, v. 33, n. 3, p. 3701.13701.4, jul. 2011.

PINA, A.; SILVA, L.F.; OLIVEIRA, Z.T.J. Mudanças climáticas: reflexões para subsidiar esta discussão em aulas de Física. Caderno Brasileiro de Ensino de Física, Santa Catarina, v. 27, n.3, p. 449-472, dez. 2010.

PORTOLÉS, J.J.S. El ozono atmosférico ¿benefactor o malhechor? Caderno Brasileiro de Ensino de Física, Santa Catarina, v.18, n.3, p.350-363, dez. 2001.

SEVERINO, A.J. Metodologia do trabalho científico. 23a ed. São Paulo: Cortez, 2007.

SILVA, L.F.; CARVALHO, L.M.A. Temática ambiental e o ensino de física na escola média: algumas possibilidades de desenvolver o tema produção de energia elétrica em larga escala em uma situação de ensino. Revista Brasileira de Ensino de Física, v. 24, n. 3, p. 342-352, set. 2002.

STEFFANI, M.H.; DAMASIO, F. Ensinando física com consciência ecológica e com materiais descartáveis, Revista Brasileira de Ensino de Física, São Paulo, v. 29, n. 4, p. 593-597, mar. 2007.

XAVIER, M.E.R. A análise do efeito estufa em textos paradidáticos e periódicos jornalísticos. Caderno Brasileiro de Ensino de Física, Santa Catarina, n.3, p. 325-349, dez. 2004 